\title{
Cardiac Free Wall Rupture after Acute Myocardial Infarction

\author{
Clinical and Pathological Analysis
}

\author{
Xing Sheng Yang, M.D., Jing Ping Sun, M.D., and \\ Da Xien Huang, M.D.
}

\section{Summary}

Clinical and pathological findings in 15 autopsy cases, 13 males and 2 females, confirming cardiac free wall rupture after AMI were reported. The incidence is $30.6 \%$ of all autopsy cases of AMI in Chinese PLA General Hospital from 1958 to 1979. The ages ranged from 46 to 79 years, 10 being above 60 years. For $73.3 \%$ it was the first AMI and $66.7 \%$ of the patients had a history of hypertension. Thirteen of the 15 patients died within 5 days after the onset of AMI and another 2 within 7 days. When the cardiac rupture occurred, the ECG generally showed bradycardia, AV-junctional rhythm, III $^{\circ} \mathrm{AV}$ block or isorhythmic ventricular rhythm and cardiac arrest.

Both the gross and microscopic AMI were examined in 13 cases. All of them had a septal infarct, but only 2 had an ECG diagnosis. Of the 6 patients with inferior MI on ECG, 5 had right and left coronary lesions worse than grade III.

The effective prevention of cardiac rupture consists of early diagnosis, control of chest pain and vomiting, prevention or treatment of hypertension or hypotension and 1 to 2 weeks of bed rest after the onset of AMI.

\section{Additional Indexing Words :}

Cardiac rupture Acute myocardial infarction Cardiac arrest Clinicopathological analysis

$\mathrm{F}$ OLLOWING the establishment of coronary care units (CGU), a striking decline in mortality from acute myocardial infarction (AMI) occurred mainly due to improved treatment of cardiac arrhythmias. However, deaths

From the Department of Cardiology, the Chinese PLA General Hospital and Military Postgraduate Medical School, Beijing, People's Republic of China.

Address for reprint: Xing Sheng Yang, M.D., Department of Cardiology, Chinese PLA General Hospital and Military Postgraduate Mcdical School, Beijing, People's Republic of China.

Received for publication July 6, 1984.

Manuscript revised March 6, 1985. 
due to cardiac rupture apparently increased. ${ }^{1)}$ Although major advances in surgical technique over the past 15 years have resulted in some successful interventions after septal or myocardial reputure due to AMI, ${ }^{2)-4}$ ) it is still difficult to diagnose this event in the early stage. The purpose of this study was to analyze the clinical and pathological findings in 15 autopsy proven cases, in an attempt to improve the diagnosis and treatment of this life threatening complication.

\section{Methods}

During the period 1958 to 1979 , of 49 consecutive autopsies done on patients who died from AMI, 15 patients had isolated free wall rupture. The clinical materials are shown in Table $\mathrm{I}$. Thirteen patients were males and over half of the males were 60-69 years old. The youngest patient was 45 years old while the oldest was 76 . The ages of the 2 female patients were 61 and 69 .

Gross and histologic estimates of the extent of coronary atherosclerosis

Table I. Clinical Findings in 15 Patients as Compared to Others

\begin{tabular}{|c|c|c|c|c|}
\hline & Present study & Norris (1980) & Feneley (1983) & Yang (1984) \\
\hline Number of patients & 15 & 20 & 12 & 42 \\
\hline Age (yr) (range) & $63(45-76)$ & $67(42-83)$ & $61(45-81)$ & $68(46-86)$ \\
\hline Male: Female & $13: 2$ & $11: 9$ & $7: 5$ & $26: 16$ \\
\hline \multicolumn{5}{|l|}{ Past history } \\
\hline Previous infarction & 4 & 1 & 2 & 3 \\
\hline Previous hypertension & 10 & 7 & 4 & 19 \\
\hline \multicolumn{5}{|l|}{ Clinical status on admission } \\
\hline No cardiac failure & 12 & 15 & - & 12 \\
\hline Mild cardiac failure & 2 & 4 & - & 23 \\
\hline Hypotension & 1 & 0 & 0 & 7 \\
\hline $\begin{array}{l}\text { Persistent or recurrent chest } \\
\text { pain }\end{array}$ & 9 & 8 & 5 & 14 \\
\hline Nausea and/or vomiting & 9 & - & - & - \\
\hline \multicolumn{5}{|l|}{ Location of infarction on ECG } \\
\hline Anterior & 5 & 12 & 5 & 30 \\
\hline Inferior & 6 & 6 & 2 & 12 \\
\hline Anterior and inferior & 4 & - & 2 & - \\
\hline High lateral & 0 & 0 & 2 & 0 \\
\hline Posterior and inferior & 0 & 0 & I & 0 \\
\hline No definite infarction & 0 & 1 & 0 & 0 \\
\hline ECG not done & 0 & 1 & 0 & 0 \\
\hline Onset of rupture (day) & $1-7$ & - & $1-11$ & $1-7$ \\
\hline $\mathrm{N}$ within 1 weck $(\%)$ & 100 & - & - & 100 \\
\hline
\end{tabular}


were made using standard techniques. Histologic sections of the coronary arteries were taken according to the methods of Roberts and Buja ${ }^{5)}$ to confirm the extent and severity of coronary disease.

\section{Results}

1. Clinical manifestation

As shown in Table I, most patients had a history of hypertension and persistent angina pectoris accompanied by nausea and vomiting. In 6 cases the blood pressure remained high after the onset of chest pain. One patient whose BP was $130 / 86$ with a heart rate of $55 / \mathrm{min}$ on admission, failed to maintain his BP. Dopamine, aramine and atropine were administered when the blood pressure dropped to $84 / 58$. Blood pressure then rapidly reached $170 / 94$ and the patient died suddenly 3 min later.

2. Bed rest following the onset of symptoms

Nine patients were not put to bed immediately after the onset of AMI. Six remained active before admission owing to uncertain diagnosis; one was restless because of chest pain following internal mammary artery ligation, which was complicated by a pneumthorax and another elderly deaf patient was unable to keep quiet because of excruciating chest pain. Two patients died during defecation. Another patient neglected medical advice and went to the toilet by himself regularly. He passed away in his bed 20 min after a bowel movement 5 days after the onset of AMI.

3. ECG alteration at the time of rupture ECG was recorded in 11 cases. Most of them showed bradycardia followed by cardiac arrest. Among these patients, 5 died when they were under constant monitoring and sequential changes were observed. One patient had persistent sinus rhythm at first which then changed to a junctional rhythm, auto-ventricular beating and finally cardiac arrest.

4. Pathologic findings

(1) Relationship between ECG location and pathologic findings is shown in Table III. In these 15 cases, 22 coronary artery branches were found to have atheromatous lesions worse than grade III. Among them, 10 were of the anterior descending branch and 4 the left circumflex branch. It is well known that marked atheromatous changes occur mainly in the left coronary artery. Clinical diagnosis of MI of the anterior septum was made in 5 , corresponding closely with location indicated by EGG. In 6 patients with inferior MI, the right coronary artery was involved in 5 cases, and among them, the left coronary artery was severely involved in 4 . The ventricular septum was examined in 13 patients, and infarction was found in all of them. 
Table II. Relationship between ECG Location and Pathological Findings in 15 Cases

\begin{tabular}{|c|c|c|c|c|c|c|c|c|c|c|c|c|}
\hline \multirow{2}{*}{ ECG location } & \multicolumn{3}{|c|}{$\begin{array}{l}\text { Atheromatous lesion } \\
\text { worse than grade III }\end{array}$} & \multicolumn{2}{|c|}{$\begin{array}{c}\text { Prevalence of } \\
\text { thrombus }\end{array}$} & \multicolumn{7}{|c|}{$\begin{array}{c}\text { Pathologic changes of } \\
\text { myocardium }\end{array}$} \\
\hline & LAD & LCA & $\mathrm{RCA}$ & Yes & No & LAA & LL & $\begin{array}{l}\text { LA+ } \\
\text { APEX }\end{array}$ & RV & RA & LV & VS \\
\hline Extensive anterior & 3 & 1 & 3 & 4 & - & 3 & 1 & 2 & - & 1 & - & 4 \\
\hline Anterior & 3 & - & - & 3 & - & 2 & - & 1 & - & - & - & 2 \\
\hline Anterior septal & 2 & - & - & 2 & - & 1 & 一 & 1 & - & - & - & 2 \\
\hline Inferior & 2 & 3 & 5 & 4 & 2 & - & 3 & - & 1 & - & 2 & 5 \\
\hline Total & 10 & 4 & 8 & 13 & 2 & 6 & 4 & 4 & 1 & 1 & 2 & 13 \\
\hline
\end{tabular}

Abbreviations: $L A D=$ left anterior descending; $L C A=$ left circumflex artery; $R C A=r i g h t$ coronary artery; $L A=$ left anterior wall; $L L=$ left lateral wall; $R V=$ right ventricular wall; $\mathrm{RA}=$ right anterior wall; $\mathrm{LV}=$ left ventricular wall; $\mathrm{VS}=$ ventricular septum.

Table III. Relationship between Diameter and Location of Cardiac Ruptures

\begin{tabular}{|c|c|c|c|c|c|}
\hline \multirow{2}{*}{$\begin{array}{l}\text { Diameter of } \\
\text { rupture }(\mathrm{cm})\end{array}$} & \multicolumn{4}{|c|}{ Location of rupture } & \multirow[b]{2}{*}{ Total } \\
\hline & $\begin{array}{c}\text { Extensive } \\
\text { anterior }\end{array}$ & Anterior & $\begin{array}{c}\text { Anterior } \\
\text { septal }\end{array}$ & Inferior & \\
\hline $0.3-$ & 1 & - & 1 & 3 & 5 \\
\hline 1.0 & 2 & 2 & 1 & 1 & 6 \\
\hline $2.0_{-}$ & - & - & - & 1 & 1 \\
\hline $3.0-3.9$ & 1 & 2 & - & 1 & 4 \\
\hline 6.5 & 1 & 一 & - & - & 1 \\
\hline Total & 5 & 4 & 2 & 6 & 17 \\
\hline
\end{tabular}

All of the patients in this series were shown to have thrombosis in the involved coronary arteries, except for 2 cases with inferior wall infarction. Double ruptures were demonstrated in 2 cases, in which the anterior wall was the site of pathology. The right ventricle was involved in 2 patients, an extensive lesion of the anterior wall in one and that of the inferior wall in another. Right ventricular rupture was found in only 1 patient.

(2) Diameter of ruptures

There were 17 ruptures in 15 cases (Table III). The diameter of the ruptures ranged from 0.3 to $6.5 \mathrm{~cm}$. All the openings appeared to be horizontal in direction, irregular in shape with ragged edges, and there was clay-colored necrotic tissue of soft consistency. The rupture occurred in a recent ventricular aneurysm in 2 patients. 


\section{Discussion}

1. Incidence of post-infarction cardiac rupture

Of the 35 autopsy series published between 1928 and 1973, cardiac rupture was found in $4 \%$ to $24 \%$ of the cases, with a mean incidence of $8 \%$ of nearly 15,000 autopsied cases of AMI.6) These figures showed no evidence that cardiac rupture as a fatal event had either increased or decreased in incidence between 1928 and 1973.

Recently Roeske et al, 7) analyzing autopsy findings from 85 patients with $\mathrm{MI}$, found that 16 patients $^{19}$ ) had died from cardiac rupture. We reported in 1984 that the incidence of cardiac free wall rupture was $1.8 \%$ in 2,312 patients with AMI and $14(0.6 \%)$ died from ventricular septum rupture in Belgium. ${ }^{8)}$ In the Beijing area, 8 cardiac ruptures were found in postmortem examinations of 43 patients dying from AMI in 1972, constituting an incidence of $18.6 \% .^{91}$ A total number of 1,544 cases of AMI were admitted to 10 hospitals in Shanghai from 1970 to 1979,473 patients $(30.7 \%$ ) died within 60 days after the onset of acute chest pain. In 17 of the 473 patients, death was due to cardiac rupture. ${ }^{10)}$ In another group in the Shanghai area, of 40 postmortem examinations, cardiac rupture was the cause of death in $9\left(22.5 \%\right.$ ) cases. $^{11}$ In our hospital, in 49 consecutive autopsies done on patients dying from AMI between 1958 and 1979, 15 cases of cardiac free wall rupture $(30.6 \%)$ were found. The above data indicate that cardiac rupture as a complication of AMI is not uncommon in our country.

2. Clinical diagnosis of cardiac rupture

The diagnosis of cardiac free wall rupture complicating AMI is comparatively difficult. Based upon observations made in 15 cases of this series, the following aspects may be of some help.

(1) When precordial pain persists or occurs repeatedly in AMI, the possibility of cardiac free wall rupture should be considered. Norris demonstrated that 8 of the 20 patients with cardiac rupture had persistent or recurrent chest pain ${ }^{1)}$ and 5 out of the 12 cases in another group ${ }^{12}$ ) had persistent chest pain. In the 15 cases of this series, precordial pain persisted in 9 cases following the occurrence of $\mathrm{MI}$, with little relief after drug therapy. In the other 6 patients, 4 suddenly developed precordial pain with deterioration of their condition. Other symptoms of impending cardiac free wall rupture include repeated attacks of vomiting and nausea which occurred in 9 of 12 cases. When the patient complains of sudden substernal pain, rapidly followed by breathlessness, cyanosis and manifestations of shock, free wall rupture should be highly suspected, especially in patients above 60 years of age.

(2) Changes in physical signs may suggest cardiac free wall rupture. 
In 13 patients with detailed records, heart sounds were feeble, an apical systolic murmur louder than grade III was present in 2 cases and pericardial rubs in 3. These signs are not uncommon in AMI. However, if they are followed by gradual expansion of the cardiac border, heart sounds become unclear and pulses become impalpable but at the same time there are no changes or only low amplitude in EGG, i.e. so-called electro-mechanical dissociation, ${ }^{13}$ the possibility of cardiac free wall rupture is rather great. It has been suggested that a low-pitched, continuous rumbling murmur with expiratory accentuation and inspiratory diminution in intensity may be heard during the course of cardiac rupture. Furthermore, cardiac rupture may manifest itself by a rough and loud systolic murmur which disappears as abruptly as it appears. The disappearance of the murmur is believed to be due to blockage of the rupture by a mural thrombus. ${ }^{14}$ )

(3) Some changes in ECG may be present before or during a free wall rupture, The predominant ECG changes include bradyarrhythmias and cardiac arrest following isorhythmic ventricular rhythm. The bradycardia is believed to be caused by derangement of vagal function following pericardial dilatation. ${ }^{14)}$ Friedman ${ }^{14}$ ) observed re-elevation or depression of ST segments during cardiac rupture, but we have not seen such phenomena in the present study. Therefore, cardiac free wall rupture should be seriously considered whenever there is a sudden appearance of bradycardia, AV junctional rhythm, third-degree $A V$ block or isorhythmic ventricular rhythm. Two patients of this series died of sudden attacks of ventricular fibrillation, and one of them showed the following sequence of events; AV junctional rhythm $\rightarrow$ isorhythmic ventricular rhythm $\rightarrow$ standstill.

(4) Precipitating factors and prevention of cardiac rupture. In the 15 cases of the present study, the surrounding area which presented changes of acute infarction varied in size, ranging from $1 \times 2 \mathrm{~cm}$ to $13 \times 9 \mathrm{~cm}$. In 11 cases there was fresh thrombus formation in the coronary artery supplying the area of rupture. Thirteen patients died within 5 days after the onset of infarction (5 days in 4, 3 in 4, 1 in 3,2 and 4 in each of the other 2), and 2 within 7 days. These factors indicate that acute blockage as the result of thrombosis of the coronary artery led to pathological changes such as interstitial hemorrhage, edema, polymorphonuclear infiltration and myolysis, which always develop within 1 week after infarction.

In the present study, it is quite obvious that lack of complete bed rest, persistent chest pain, nausea, vomiting and the persistence of hypertension are the important precipitating factors. As to the prevention of cardiac rupture, it is of utmost importance to make an early diagnosis, therefore complete mental and physical rest should be enforced at the onset of AMI. 
We believe that complete bed rest for I week is mandatory after the attack of AMI. In complicated cases or the very elderly, it is necessary to prolong the period of complete bed rest to 2 weeks or more.

\section{References}

1. Norris RM, Sammel NL: Predictor of late hospital death in AMI. Progr Cardiovasc Dis 23: 129,1980

2. Caliek A, Kerth W, Barwour D, Cohn K: Successful surgical therapy of ruptured myocardium. Chest 66: 188,1974

3. Einsenmann B, Bareiss P, Pacifico AD, Jeanblanc B, Kretz JG, Bachrel B, Warter J, Kieny R: Anatomic, clinical and therapeutic features of acute cardiac rupture. $\mathrm{J}$ Thorac Cardiovasc Surg 76: 78, 1978

4. Coma-Canella I, Lopez-Sendon J, Gonzalez LN, Ferrufino O, Spain M: Subacute left ventricular free wall rupture following AMI. Bedside hemodynamics, differential diagnosis and treatment. Am Heart J 106: 278, 1983

5. Roberts WC, Buja LM: The frequency and significance of coronary artery thrombi and other observations in fatal AMI : a study of 107 necropsy patients. Am J Med 52: 425, 1972

6. Bates RJ, Beutler S, Resnekov L, Anagnostopoul CE: Cardiac rupture. Challenge in diagnosis and management. Am J Cardiol 40: 429, 1977

7. Roeske WR, Savage RM, O'Rourke RA, Bloor CM: Clinicopathologic correlations in patients after myocardial infarction. Circulation 63: 36, 1981

8. Yang XS, De Geest H, Willems JH: Factors influencing the prognosis of acute myocardial infarction. Kethetic Leuven University, Leuven, Belgium, p 183, 1984

9. Yang XS, Sun JP: Cardiovascular diagnosis and treatment. People's Health Publishing House, Beijing, p 152, 1976

10. Shanghai Myocardial Infarction Research Cooperation Group: Clinical analysis of AMI in Shanghai. Chinese J Internal Med 23: 273, 1984

11. Shanghai Institute of Cardiovascular Research: Clinicopathological analysis in 40 paticnts of acute myocardial infarction. Chinese J Internal Med 15: 228, 1976

12. Feneley MP, Chang VP, O'Rourke MF: Myocardial rupture after AMI. Ten years review. Br Heart J 49: 550, 1983

13. Cobbs BW, Hatcher ChR, Robinson PH: Cardiac rupture. Three operations with two long-term survivals. JAMA 223: 532, 1973

14. Friedman HS, Kuhn L, Katz AM: Clinical and electrocardiographic features of cardiac rupture following AMI. Am J Med 50: 709, 1971 